\title{
PERANCANGAN ANIMASI MOTION GRAPHIC SEBAGAI MEDIA PROMOSI STMIK AKBA
}

\author{
Muhammad Rizal $^{1)}$, Butsiarah ${ }^{2)}$, Muhammad Ashar Pahany ${ }^{3)}$ \\ ${ }^{1,2,3)}$ Teknik Informatika STMIK AKBA Makassar \\ email : rizal@akba.ac.id ${ }^{1)}$,butsiarah@akba.ac.id ${ }^{2}$, ashar@gmail.com ${ }^{3)}$
}

\begin{abstract}
Abstraksi
Penelitian ini bertujuan untuk merancang dan mengimplementasikan media promosi STMIK AKBA dalam bentuk video animasi motion graphic agar lebih dikenal oleh masyarakat luas khususnya di Sulawesi Selatan. Metode pada penelitian ini menggunakan metode research and development yang dilakukan pada STMIK AKBA Penelitian ini mengkaji media yang digunakan oleh STMIK AKBA dalam mempromosikan kampus. Pada penelitian ini, peneliti menyatakan bahwa penggunaan Video Motion Graphic pada media promosi kampus dengan memperoleh hasil pengujian oleh ahli materi sebesar $98 \%$ dan ahli media sebesar $92 \%$ dinyatakan sangat layak dijadikan sebagai media penyampaian informasi perusahaan.
\end{abstract}

\section{Kata Kunci :}

Multimedia, Video, Animasi, Motion Graphic, Media Promosi

\begin{abstract}
This research aims to design and implement a media campaign STMIK AKBA in the form of animated motion graphic video that is better known by the general public especially in South Sulawesi. The method in this study uses the research and development method carried out at STMIK AKBA. This research examines the media used by STMIK AKBA in promoting the campus. In this study, the researcher stated that the use of Video Motion Graphic on campus promotion media by obtaining $98 \%$ of the test results by material experts and $92 \%$ of media experts was declared very suitable as a medium for conveying company information.
\end{abstract}

Keywords :

Multimedia, Video, Animation, Motion Graphic, Media Promotion

\section{Pendahuluan}

Perkembangan teknologi penyajian informasi saat ini semakin pesat dengan adanya berbagai macam media penyajian yang memiliki karakter dan keunggulan masing-masing. Seiring berkembangnya penyajian informasi pemanfaatan motion graphic juga memberikan daya tarik tersendiri sebagai media promosi kepada audiens. Melalui sarana media promosi, masyarakat dapat menerima informasi yang jelas mengenai produk yang ditawarkan oleh suatu perusahaan atau organisasi. Seiring perkembangan teknologi informasi dan perubahan kebiasaan masyarakat maka media promosi pun juga ikut berkembang. Dalam hal ini salah satunya adalah motion graphic. Salah satu variasi media dalam menyajikan informasi atau yang biasa disebut media promosi adalah motion graphic. Motion graphic menggabungkan semua elemen multimedia seperti gambar, suara, teks, dan animasi dalam menyajikan informasi yang menyenangkan sehingga audiens yang menyaksikan lebih tertarik untuk mengikuti informasi yang disajikan.

Media promosi yang menggunakan teknik motion graphic semua infromasi yang disajikan dapan dengan cepat dimengerti, karena informasi yang disampaikan berbentuk visual dan audio. Media promosi berbentuk video dengan Teknik motion graphic menggunakan objek flat design sangat menarik dan inovatif sehingga mempunyai daya tarik tersendiri bagi yang melihatnya [1].

Sebagai Sekolah Tinggi, STMIK AKBA melakukan aktivitas promosi untuk memperkenalkan kampus dan meningkatkan minat calon peserta didik untuk menempuh pendidikan di kampus STMIK AKBA. Dalam aktivitasnya beberapa bentuk media promosi telah digunakan seperti brosur, poster, spanduk dan website juga media promosi berupa video namun STMIK AKBA belum memiliki variasi media promosi dalam bentuk animasi motion graphic yang relevan dengan target audiensnya.

STMIK AKBA membutuhkan sebuah variasi media promosi berbentuk animasi motion graphic sebagai media promosi yang menarik, modern yang mampu menyajikan informasi secara efektif sehingga memberikan daya tarik bagi target audiensnya. Selain itu media promosi ini juga berfungsi sebagai konten Brand Awareness bagi STMIK AKBA.

Berdasarkan latar belakang di atas, maka penulis tertarik untuk merancang animasi motion graphic sebagai media promosi STMIK AKBA agar target 
audiens atau calon peserta didik tertarik melanjutkan jenjang pendidikannya di kampus STMIK AKBA.

\section{Tinjauan Pustaka}

\section{Multimedia}

Istilah multimedia terdiri dari dua kata yaitu multi dan media. Multi dalam bahasa latin disebut nouns yang memiliki arti banyak, sedangkan media diambil dari bahasa latin yaitu medium yang memiliki arti sebagai perantara untuk menyampaikan atau membawa sesuatu. Berdasarkan arti dua kata tersebut, dapat disimpulkan multimedia adalah perpaduan teks, animasi, gambar, video dan lainlain, yang kemudian disatukan kedalam file digital dengan bantuan komputer yang berguna sebagai perantara penyampaian informasi atau pesan [2].

Berdasarkan definisi para ahli, perpaduan berbagai macam media teks, audio, grafis animasi dan video secara interaktif yang akan disampaikan menggunakan komputer atau peralatan elektronik untuk menyampaikan informasi disebut sebagai multimedia [3].

\section{Pengembangan Multimedia}

Pengembangan multimedia terdiri dari 6 tahapan, yaitu yaitu concept (konsep), design (desain), material collecting (pengumpulan materi), assembly (pembuatan), testing (pengujian), dan distribution (pendistribusian) [4].

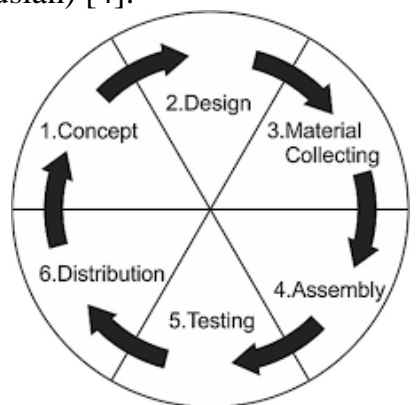

Gambar 1 Metode Pengembangan Multimedia

\section{Concept}

Tahap concept (konsep) adalah tahap untuk menentukan dan siapa penggunanya (identifikasi audiens). Dasar aturan untuk perancangan juga ditentukan pada tahap ini, agar hasil akhir dari produk yang dirancang sesuai yang diharapkan. Tahap ini menjadi bagian yang penting dilakukan dalam merancang produk multimedia karena akan menjadi acuan untuk tahap selanjutnya.

\section{Design}

Tahap design (desain) adalah tahap pembuatan spesifikasi mengenai alur video, gaya, tampilan maupun bahan yang dibutuhkan dalam video animasi motion graphic. Spesifikasi dibuat secara rinci agar pada tahap selanjutnya yaitu material colletion dan assembly, pengambilan keputusan baru tidak diperlukan lagi karena sudah ditentukan pada tahap ini. Pada tahap ini menggunakan storyline dan storyboard untuk menggambarkan alur tiap bagian pada video atau yang biasa diistilahkan scene.

\section{Material Collection}

Tahapan ini merupakan tahap pengumpulan bahanbahan yang dibutuhkan dalam membuat video promosi ini. Bahan-bahan itu meliputi gambar, foto, sketsa, animasi, music, narasi, dan lain-lain. Pada tahap ini dapat dikerjakan secara parallel dengan tahapan selanjutnya yaitu tahap assembly.

\section{Assembly}

Tahap assembly merupakan tahap pembuatan dan penyatuan semua material yang telah dikumpulkan menjadi satu kesatuan dan menghasilkan produk video promosi motion graphic. Pada tahap ini storyboard menjadi acuan dalam pembuatannya agar produk yang dihasilkan sesuai dengan alur cerita yang telah disusun. Pada tahap ini

biasanya memaksimalkan penggunaan perangkat lunak authoring seperti Adobe Illustrator, Adobe Photoshop, Adobe Premiere, Adobe After Effect, Adobe Audition dan lain-lain.

\section{Testing}

Tahap testing (pengujian) merupakan tahap lanjutan setelah seluruh rangkaian proses produksi dengan mengevaluasi kembali video apakah ada yang kurang atau tidak. Selain itu pada tahap ini juga dilakukan pengujian alpha (alpha test) yang pengujiannya dilakukan oleh pembuatnya sendiri, setelah itu dilanjutkan dengan pengujian beta yang melibatkan pengguna akhir.

\section{Distribution}

Tahap distribution (distribusi) merupakan tahap selanjutnya setelah produk selesai diuji. Produk yang dihasilkan disimpan dalam suatu format media penyimpanan. Tahap ini juga produk mulai di publikasi secara umum kepada semua audiens, biasanya pada tahap ini aka nada evaluasi dari saran yang diberikan oleh audiens untuk tahap konsep produk selanjutnya.

\section{Konsep Visual}

Konsep visual dalam mempromosikan atau memperkenalkan desain Media promosi harus dapat memilih konsep visual yang menarik, kreatif, memiliki daya tarik tersendiri yang sesuai dengan tujuan yaitu meningkatkan daya Tarik warga dengan video animasi yang bermanfaat dan mengedukasi. Kegiatan promosi harus efektif, perspektif, dan kreatif agar mencapai tujuan yang diharapkan. Promosi yang efektif adalah promosi yang berbeda dengan promosi yang lainnya. Promosi efektif perlu dilakukan karena jika tidak maka dikhawatirkan promosi tersebut tidak kompetitif dan tidak dapat bersaing.

\section{Media Promosi}


Menurut Kamus Besar Bahasa Indonesia Dalam Jaringan/Online (KBBI Daring) media dapat diartikan sebagai: 1.Alat; 2. Alat (sarana) komunikasi seperti koran, majalah, radio, televisi, film, poster dan spanduk. Promosi adalah salah satu variable yang digunakan perusahaan dalam mengadakan komunikasi dengan pasarnya, bertujuan untuk memberitahu bahwa suatu produk itu ada dan memperkenalkan produk serta memberikan keyakinan akan produk tersebut kepada pembeli dan calon pembeli [4].

\section{Motion Graphic}

Motion graphic merupakan salah satu cabang ilmu desain grafis, dimana dalam motion, elemen elemen desain seperti bentuk, raut, ukuran, arah, tekstur yang terdapat di dalamnya, dengan secara sengaja digerakkan atau diberi pergerakan agar tampak hidup [5].

\section{Storyline}

Storyline atau alur dibuat dari pengembangan ide cerita yang didasarkan pada gagasan dasar dan disesuaikan dengan panduan dari creative work plan. Storyline adalah suatu panduan kerja dalam proses pembuatan sebuah informasi yang berisi konsep naskah dari informasi yang akan dikerjakan, sehingga penerapan informasi menjadi suatu perancangan dan implementasi mempunyai panduan yang jelas [6].

\section{Storyboard}

Storyboard adalah sebuah Teknik atau metode yang digunakan untuk memvisualisasikan antarmuka (interface) berupa gambar dan teks. Gambar-gambar dalam storyboard melukiskan lajur visual dalam script. Sedangkan teks melukiskan kolom atau lajur audio atau sound dalam naskah [6].

\section{Adobe Premiere Pro}

Adobe Premiere Pro merupakan software yang umum digunakan untuk mengedit video baik untuk keperluan film, iklan dan lain-lain. Adobe Premiere Pro memiliki keunggulan bisa menerima hampir semua ekstensi video seperti .avi, .mov, .mp4 dan lain-lain.

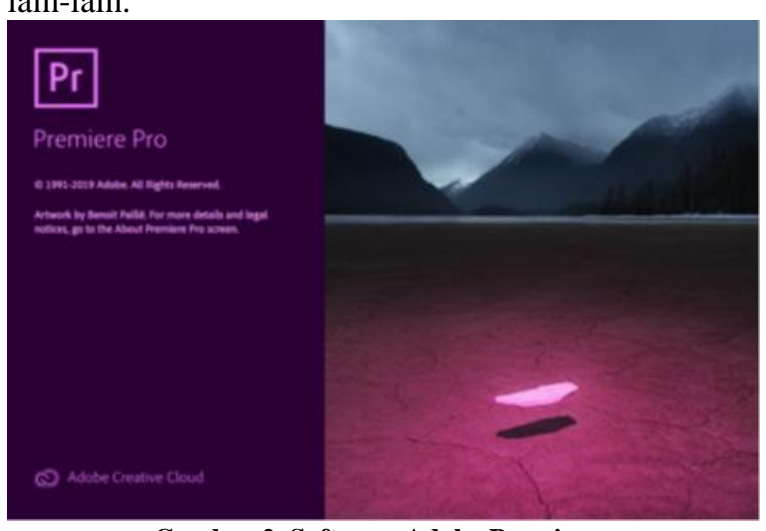

Gambar 2. Software Adobe Premiere

\section{Adobe After Effects}

Merupakan salah satu perangkat lunak editing video yang sangat popular dan sudah diakui

kecanggihannya. After Effects adalah software yang digunakan untuk membuat efek transisi. Adobe After Effects merupakan salah satu software animasi multimedia terbaik yang telah menyediakan semua kebutuhan para amatir maupun profesional untuk pembuatan animasi atau motion graphics dan visual effect.

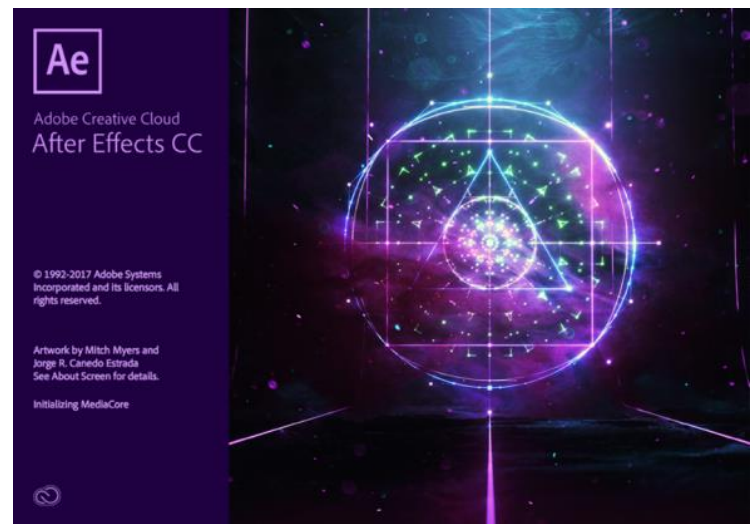

Gambar 3 Software Adobe After Effects

\section{Adobe Audition}

Adobe Auditionadalah sebuah software dari Adobe System untuk merekam, mengedit, serta mencampur dan mastering music. Adobe Audition terbagi menjadi 3 area kerja utama, yaitu edit view, multitrack view, dan CD Project View.

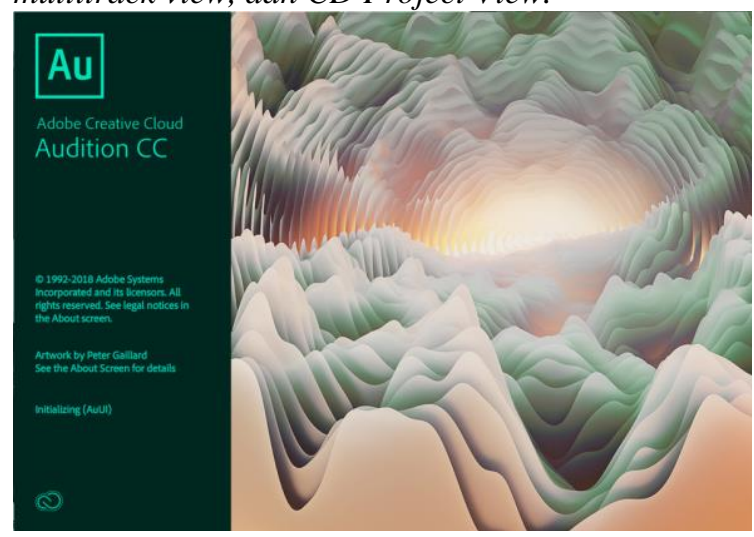

Gambar 4. Software Adobe Audition

\section{Metode Penelitian}

Penelitian ini bertujuan untuk mengembangkan media promosi STMIK AKBA. Berkaitan dengan penelitian penulis yang berjudul Perancangan Animasi Motion Graphic Sebagai Media Promosi STMIK AKBA, maka untuk memperkuat landasan dari penelitian, maka penulis menetapkan metode penelitian dan pengembangan (Research and Development) agar pengembangan dari media promosi tersebut dapat memenuhi standar kualitas bahwa metode Research and Development adalah penelitian yang digunakan untuk menghasilkan 
produk tertentu dan menguji keefektifan produk tersebut [7].

\section{Prosedur Pengembangan}

Model pengembangan produk yang digunakan dalam penelitian ini adalah model pengembangan yang dikemukakan oleh Luther. Model pengembangan multimedia terdiri dari enam tahapan, yaitu concept (pengonsepan), design (proses desain), material collecting (pengumpulan materi), assembly (pembuatan), testing (pengujian) dan distribution (pendistribusian) [8].

\section{Konsep}

Pengonsepan merupakan salah satu bagian awal dan bagian utama dari tahap pra produksi. Membutuhkan kreatifitas dan inovasi agar mendorong kita untuk menemukan ide menarik. Pada tahapan ini konsep dan pembuatan alur cerita (storyline) dikerjakan. Promosi mengenai STMIK AKBA dalam bentuk video animasi motion graphic ini adalah salah satu upaya untuk memperkenalkan dan menjangkau lebih banyak lagi audiens. Perancangan motion graphic ini diharapkan dapat memberikan informasi mengenai STMIK AKBA secara menarik dan menyenangkan kepada audiens calon mahasiswa STMIK AKBA.

\section{Pengumpulan Material}

Pada tahap ini peneliti mengumpulkan semua bahan yang telah disiapkan untuk nantinya diolah menjadi animasi motion graphic. Mengumpulkan gambar maupun refrensi visual, backsound, narasi dalam bentuk audio.

\section{Pembuatan}

Pada tahapan ini merupakan tahap produksi, yang dimana pada tahap inilah semua komponen yang telah dikumpulkan kemudian diolah dan dianimasikan menggunakan software Adobe After Effect. Semua materi digerakkan atau dianimasikan satu persatu pada setiap bagian lalu dirender perbagian kemudian disatukan kembali dengan material lainnya berupa narasi dari voice over, music latar atau backsound, efek suara khusus dan diberi efek transisi perpindahan gambar, setelah semua proses telah dilakukan dan telah rampung maka proses selanjutnya yang dilakukan adalah proses export video animasi motion graphic ke dalam bentuk format mp4.

\section{Testing (pengujian)}

Pada tahap testing peneliti mengujikan hasil produk video yang telah selesai diproduksi dilakukan oleh user pada lingkungan pengembangan (alpha test). Setelah dinilai selesai dan sudah layak untuk diuji kemudian selanjutnya dilakukan uji kepada ahli media dan ahli materi (beta test). Setelah mendapatkan beberapa revisi dan melakukan perbaikan kemudian peneliti mengujikan kembali produk yang telah direvisi kepada ahli media dan ahli materi untuk mendapatkan penilaian dari kedua ahli apakah revisi yang telah dilakukan telah sesuai dengan apa yang diharapkan pada revisi tahap awal yang dilakukan. Kemudian setelah itu dilakukan uji skala kecil dan skala besar sebagai tahap akhir dari pengujian.

\section{Pendistribusian}

Setelah tahap pengujian kemudian produk siap untuk digunakan dan dipublikasikan oleh STMIK AKBA menggunakan format mp4 melalui media distribusi online seperti media social dan website. Setelah publikasi berjalan aka nada evaluasi sebagai bahan untuk membuat project selanjutnya.

\section{Hasil dan Pembahasan \\ Storyline}

Pada project media promosi berbasis video animasi motion graphic ini alur cerita dan narasinya atau storylinenya dibuat lebih santai dan penulis memilih peremuan sebagai pengisi suara pada project ini agar kesan yang ditimbulkan lebih menyenangkan dan tidak kaku serta dapat diterima oleh target audiens STMIK AKBA. Dan storyline ini dikembangkan menjadi naskah cerita sebagai berikut: "Hai sobat, tau gak teknologi yang kian maju bukan hal yang baru, dan akan terus berkembang mengikut zaman. Semakin pesatnya perkembangan teknologi informasi semakin besar pula peluang untuk bekarir dibidang IT dengan menjadi pengusaha ataupun berkarir di perusahaan-perusahaan besar.

Nah, Apakah kamu punya mimpi berkarir di bidang Komputer atau IT? tapi kamu bingung mau mulai darimana? bingung pilih jurusan dan kampusnya dimana? jawabannya ada di Sekolah Tinggi Manajemen Informatika dan Komputer AKBA Sekolah Tinggi Manajemen Informatika dan Komputer AKBA atau disingkat STMIK AKBA adalah sekolah tinggi swasta yang berkonsentrasi pada bidang informatika dan komputer, sekolah ini berdiri sejak 10 Februari 1995. Visi STMIK AKBA adalah Menjadi Perguruan Tinggi Teknologi Informasi yang Unggul dan Kompetitif Program Studi apasih yang ada di STMIK AKBA? Program Studi yang ada di STMIK AKBA adalah S1 Sistem Informasi, S1 Teknik Informatika, dan semua program studinya telah terakreditasi B oleh Badan Akreditasi Nasional Perguruan Tinggi, di STMIK AKBA tersedia kelas reguler, Sabtu-Ahad dan kelas malam dengan fasilitas laboratorium dan ruang kelas yang mendukung proses pembelajaran.

\section{Konsep Visual}

Konsep visualiasi yang digunakan pada motion graphics ini yaitu gaya gambar kartun sederhana dengan warna solid, sedikit bergradasi, dan tanpa outline. Pada motion graphic ini menggunakan beberapa Tipografi atau huruf beberapa jenis huruf tidak berkait seperti gotham, barlow dan sweat 
purple, agar media promosi berbasis video animasi motion graphic ini dapat menyampaikan pesan yang informatif dan mudah dipahami oleh audiens.

Jenis huruf yang digunakan juga bisa selaras dan bersinergi dengan desain animasi yang ditampilkan. Hal ini bertujuan agar estetika dari video ini tetap terjaga. Warna yang dominan digunakan adalah warna biru dan merah sebagai warna identitas brand dari STMIK AKBA. Adapun warna lain pada beberapa bagian video hanya sebagai warna pendukung dan pemanis agar tampak dinamis dan memberikan kesan hidup pada media promosi berbasis video animasi motion graphic yang dibuat.

\section{Pembahasan}

Hasil implementasi merupakan hasil akhir dari seluruh rangkaian setelah melalui proses concept (konsep), design (desain), material collecting pengumpulan materi), assembly (pembuatan), testing (pengujian).

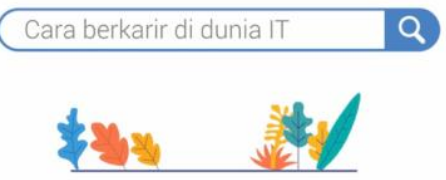

Gambar 5. Opening Video

Shoot pada gambar 5. merupakan hasil jadi untuk opening media promosi berbasis video animasi motion graphic STMIK AKBA, dengan konsep penelusuran cara berkarir di dunia teknologi informasi.

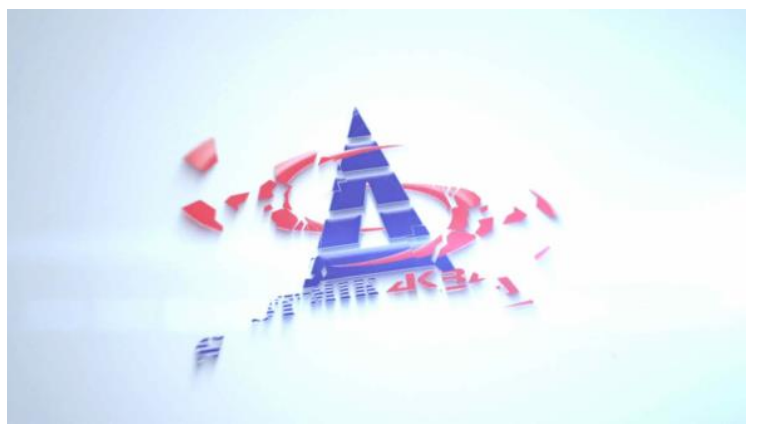

Gambar 6. Bumper Logo STMIK AKBA

Gambar 6. menunjukkan shoot berikutnya yang menampilkan bumper logo akba sebelum masuk ke bagian inti dari video promosi ini.

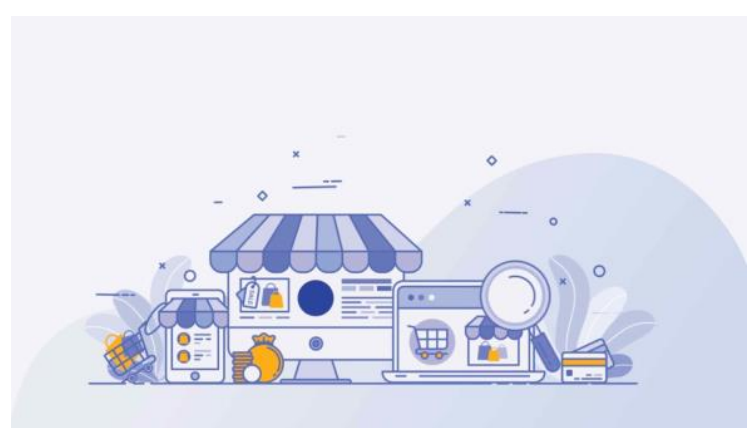

Gambar 7. Ilustrasi pesatnya teknologi informasi

Setelah itu berpindah ke bagian shoot yang mengilustrasikan perkembangan teknologi sesuai dengan rekaman narasi yang bacakan oleh pengisi suara.
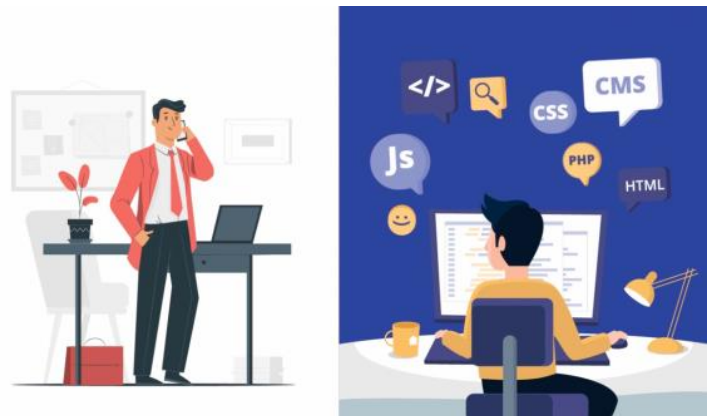

Gambar 8. Profesi dibidang Teknologi Informasi

Pada bagian ini menampilkan dua orang, sebelah kiri sebagai pengusaha yang karakternya digambarkan mengenakan jaz yang sedang menerima telepon, dan sebelah kanan adalah orang yang berprofesi di dunia IT atau programmer yang sedang melakukan aktivitas membuat program.

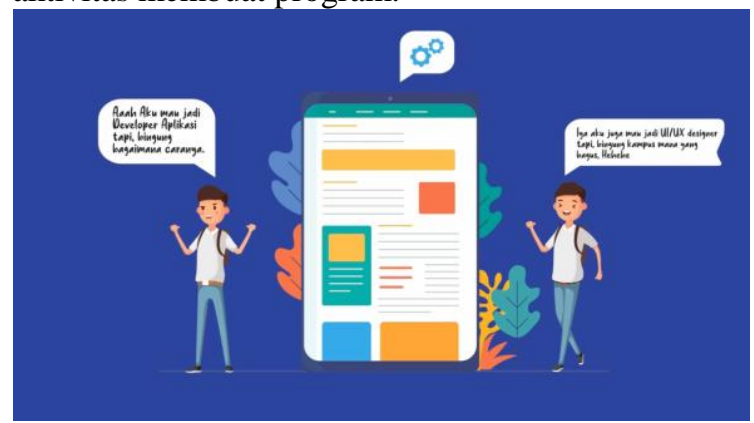

Gambar 9. Dua orang anak SLTA

Pada shoot ini menggambarkan dua orang anak SLTA yang ingin punya karir profesional pada bidang IT dan komputer dan ingin melanjutkan pendidikannya pada sekolah tinggi teknologi informasi dan komputer. 


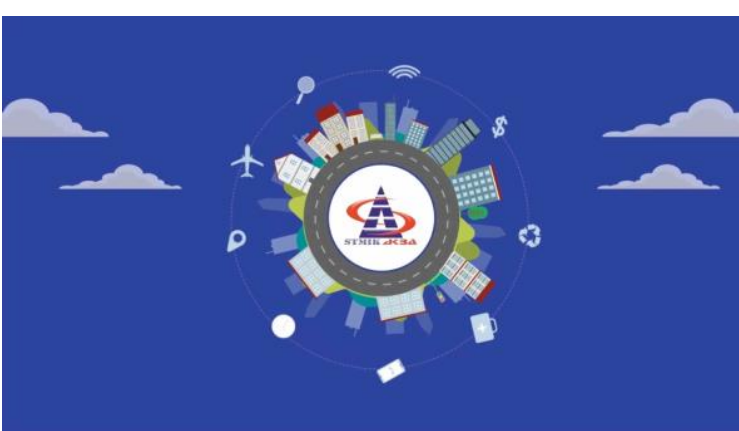

Gambar 10. Ilustrasi STMIK AKBA

Shoot ini menampilkan logo STMIK AKBA yang terpusat di tengah objek yang memiliki makna bahwa STMIK AKBA hadir sebagai solusi untuk perguruan tinggi terbaik dibidang teknologi informasi dan komputer.

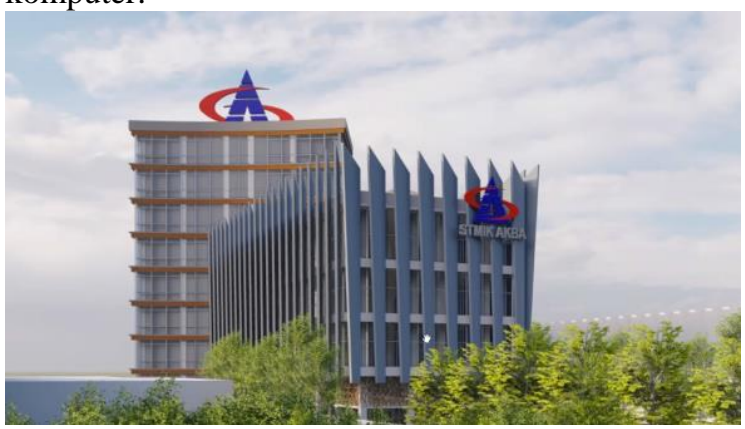

Gambar 11. Gedung Utama STMIK AKBA

Shoot ini menampilkan gedung utama kampus STMIK AKBA dalam perspektif tampak atas.

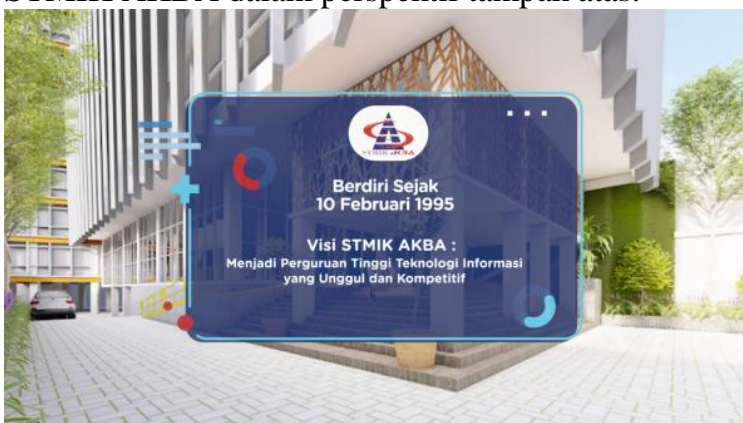

Gambar 12. Menampilkan Tanggal Berdirinya Kampus STMIK AKBA

Pada gambar gambar 12. menampilkan bagian depan Gedung utama STMIK AKBA lalu kemudian menampilkan tanggal berdiri dan visi STMIK AKBA sesuai alur narasi dari video.

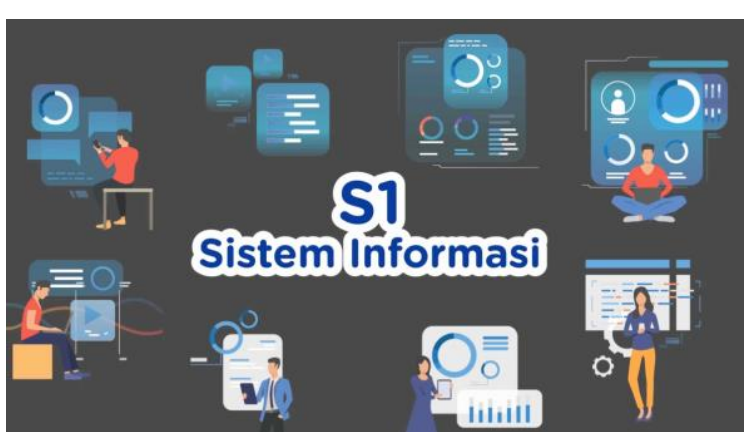

Gambar 13. Prodi Sistem Informasi
Pada bagian ini menampilkan program studi yang ada di STMIK AKBA yaituS1 Sistem Informasi dan diberi ilustrasi pendukung yang juga dianimasikan.

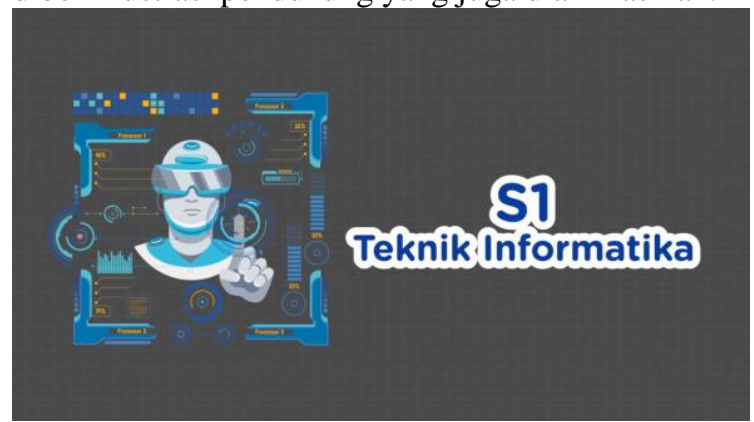

Gambar 14. Prodi Teknik Informatika

Lalu langsung berpindah pada shoot ini yang menampilkan program studi yang ada di STMIK AKBA yaitu teknik informatika.

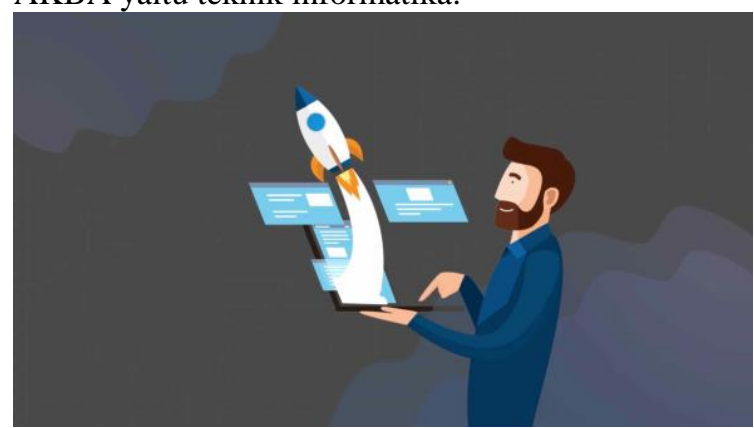

Gambar 15. Ilustrasi Pendukung

Shoot ini merupakan ilustrasi pendukung dan menjadi transisi ke shoot selanjutnya pada video ini.

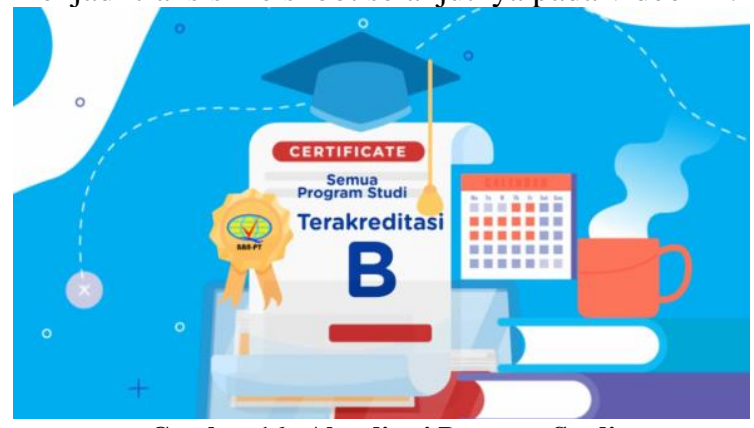

Gambar 16. Akreditasi Program Studi

Dari ilustrasi pendukung sebelumnya lalu berpindah pada shoot ini yang menampilkan akreditasi program studi di STMIK AKBA.

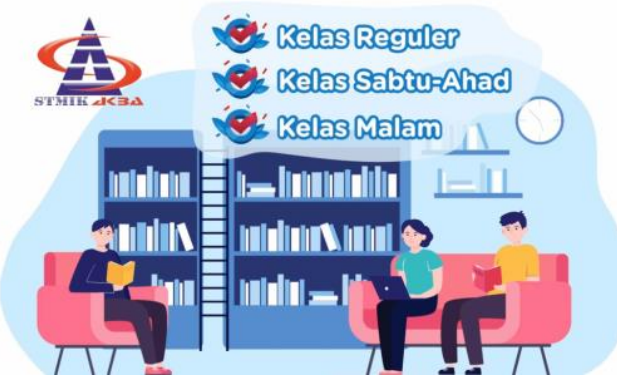

Gambar 17. Kelas yang ditawarkan 
Kemudian menampilkan sekelompok mahasiswa yang sedang berdiskusi dan menampilkan jenis kelas yang ada di STMIK AKBA.

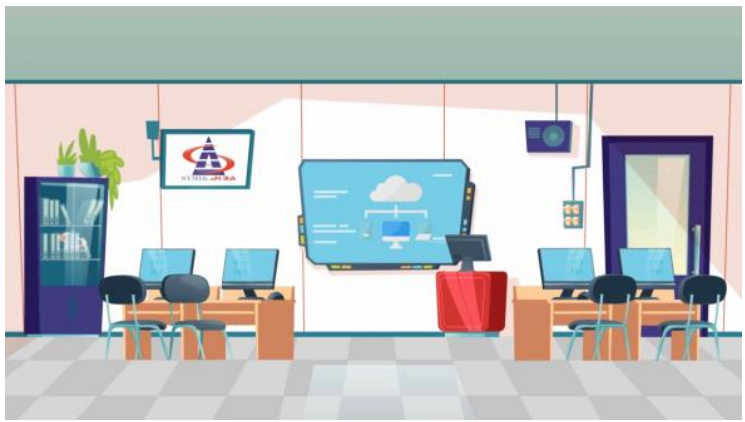

Gambar 18. Ilustrasi Laboratorium

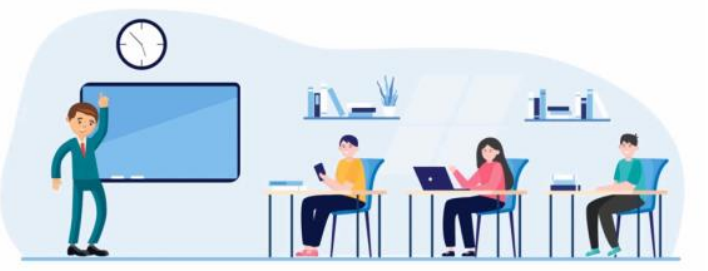

Gambar 19. Ilustrasi aktifitas belajar mengajar

Dua shoot di atas menggambarkan fasilitas laboratoriuam dan ruang kelas pada di STMIK AKBA yang mendukung proses belajar mengajar.

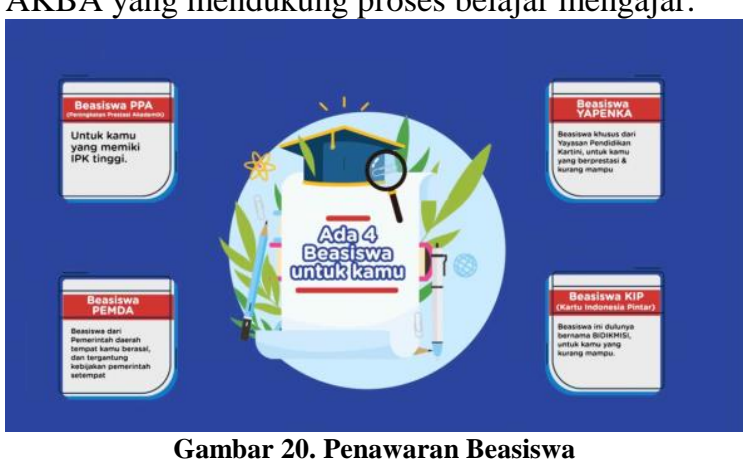

Shoot di atas menginformasikan beasiswa apa saja yang ada di STMIK AKBA yang akan muncul satu persatu.

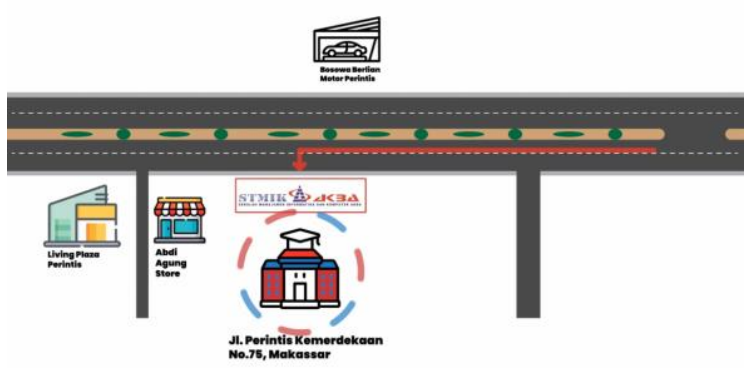

Gambar 21. Lokasi Kampus STMIK AKBA

Shoot ini menampilkan denah jalan dan beberapa gedung yang ada di sekitar STMIK AKBA untuk menggambarkan lokasi kampus STMIK AKBA yang sangat mudah diakses.

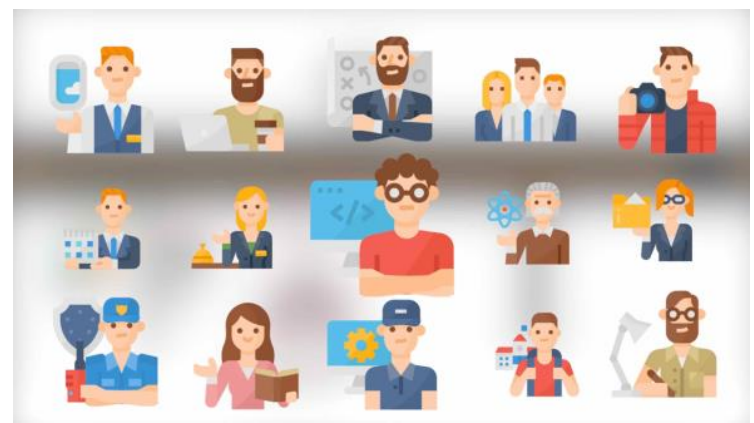

Gambar 22. Ilustrasi Berbagai Profesi IT

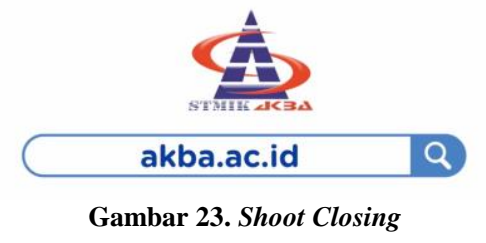

Kesimpulan dan Saran

Berdasarkan dari hasil perancangan animasi motion graphic sebagai media promosi STMIK AKBA, penulis dapat menyimpulkan bahwa :

1. Pada perancangan animasi motion graphic sebagai media promosi STMIK AKBA ini melalui beberapa tahapan produksi yaitu Pembuatan Konsep, Desain. Pengumpulan material, Produksi/pengerjaan, uji coba, dan pendistribusian. Pada tahap pembuatan konsep, desain, dan pengumpulan material yaitu dilakukan dengan melibatkan Wakil Ketua 4 Bidang Kerjasama dan Promosi STMIK AKBA dan kemudian masuk ke tahap produksi/pengerjaan yang meliputi pengerjaan dari objekobjek yang telah disusun pada storyboard kemudian didesain dan dianimasikan atau motion pada objek yang telah dikerjakan. Setelah semua proses editing selesai dan video telah dikemas dalam format Mp4, produk yang dihasilkan kemudian diuji kelayakannya dan tahap akhir yaitu pendistribusian.

2. Implementasi perancangan animasi motion graphic sebagai media promosi STMIK AKBA diperoleh dari hasil pengujian ahli materi sebesar $98 \%$ dan pengujian ahli media sebesar $92 \%$ sehingga dapat diimplementasikan ke pengguna dengan hasil yang diperoleh dan dinyatakan sangat layak dijadikan sebagai media promosi.

\section{Daftar Pustaka}

[1] I. A. Razaq, The Magic of MOVIE EDITING. Jakarta : MediaKita, 2011

[2] H. S. Zainiyati, Pengembangan Media Pembelajaran Berbasis ICT (Konsep dan Aplikasi pada Pembelajaran Pendidikan Agama Islam). Jakarta: Kencana, 2017.

[3] Munir, Multimedia Konsep dan Aplikasi dalam Pendidikan. Bandung: Alfabeta, 2015.

[4] A. S. Madjadikara, Bagaimana Biro Iklan Memproduksi Iklan. Jakarta: PT Gramedia Pustaka, 2005. 
[5] N. C. Umam, Perancangan Motion Graphic Pengenalan Batik Gemawang Khas Kabupaten Semarang. Yogyakarta: Institut Seni Indonesia, 2016.

[6] I. S. Sukarno, Perancangan Motion Graphic ilustrarif Mengenai Majapahit untuk PemudaPemudi. Bandung: Fakultas Seni Rupa dan Desain (FSRD) ITB, 2008.

[7] Sugiyono, Metode Penelitian Kuantitatif, Kualitatif dan $R \& D$.Bandung: Alfabeta, 2015.

[8] I. Binanto, Multimedia Digital Dasar Teori dan Pengembangannya. Yogyakarta: Andi Offset, 2010. 